\title{
Scleroderma Renal Crisis Presenting as Posterior Reversible Encephalopathy Syndrome
}

\author{
Aditya Bhagvat ${ }^{1}$, Shilpa Abhay Gaidhane ${ }^{2}$, Anusha Gupta ${ }^{3}$, Nazli Khatib ${ }^{4}$, Priti Abhay Karabdhajane ${ }^{5}$ \\ 1, 2,3 Department of Medicine, Jawaharlal Nehru Medical College, Datta Meghe Institute of Medical Science, Wardha, \\ Maharashtra, India. ${ }^{4}$ Department of Physiology, Division of Evidence Synthesis, School of Epidemiology and Public \\ Health, Jawaharlal Nehru Medical College, Datta Meghe Institute of Medical Science, Wardha, Maharashtra, India. \\ ${ }^{5}$ Department of Research \& Development, Jawaharlal Nehru Medical College, Datta Meghe Institute of Medical \\ Science, Wardha, Maharashtra, India.
}

\section{INTRODUCTION}

Systemic sclerosis (SSc) is an autoimmune disorder, characterised by inflammation and fibrosis in the skin and internal organs. The prevalence of systemic sclerosis is 1 / 100,000 of the Indian population. Patients with systemic sclerosis may have lifethreatening renal complications of the disease. Scleroderma renal crisis (SRC) is a life-threatening renal complication that affects $5-10 \%$ of patients with systemic sclerosis. ${ }^{1}$ It is commonly observed in females with diffuse cutaneous sclerosis. The most common presentations of scleroderma renal crisis is abrupt onset of hypertension, acute renal failure, headaches, and pulmonary oedema. Risk factors for SRC are a diffuse variety of systemic sclerosis, ${ }^{2,3}$ high dose corticosteroid use, topoisomerase III antibodies. There is an association of SRC with the simultaneous presence of microangiopathic haemolytic anaemia, thrombocytopenia, haemodialysis. In this case report, we present the youngest female patient of systemic sclerosis presenting with posterior reversible encephalopathy syndrome and scleroderma renal crisis.

Systemic sclerosis is an autoimmune systemic connective tissue disease. Renal involvement in systemic sclerosis is seen in ten percent of patients. Scleroderma renal crisis is a catastrophic, lethal, and rare complication of systemic sclerosis. Headache, episodic accelerated hypertension, and pulmonary oedema are the modes of presentation.

We report a case of an 18-year-old girl, known case of diffuse cutaneous systemic sclerosis on a low dose of steroid, presenting with status epilepticus, loss of vision, and accelerated hypertension. Her laboratory examination revealed a recent increase in blood urea nitrogen and serum creatinine. Her magnetic resonance imaging (MRI) was suggestive of posterior reversible encephalopathy syndrome.

She recovered neurologically after anti-epileptic therapy, ramipril, and diuretics. Her vision improved. But she persists to have a renal injury. At the time of discharge and at one month follow up patient did not require dialysis.

We emphasize posterior reversible encephalopathy syndrome (PRES) may be the presenting feature of SRC and the use of angiotensin-converting enzyme inhibitors (ACEi) for rapid recovery of SRC.

\author{
Corresponding Author: \\ Dr. Shilpa Abhay Gaidhane, \\ Department of Medicine, \\ Jawaharlal Nehru Medical College, \\ Datta Meghe Institute of Medical Science, \\ Wardha, Maharashtra, India. \\ E-mail: drshilpagaidhane@gmail.com
}

DOI: $10.14260 / \mathrm{jemds} / 2020 / 876$

How to Cite This Article:

Bhagvat A, Gaidhane S.A, Gupta A, et al. Scleroderma renal crisis presenting as posterior reversible encephalopathy syndrome. J Evolution Med Dent Sci 2020;9(52):4009-4011, DOI: 10.14260/jemds/2020/876

Submission 08-09-2020,

Peer Review 01-11-2020,

Acceptance 08-11-2020,

Published 28-12-2020.

Copyright (c) 2020 Aditya Bhagvat et al. This is an open access article distributed under Creative Commons Attribution License [Attribution 4.0 International (CC BY 4.0)] 


\section{PRESENTATION OF CASE}

An 18-year-old girl was brought to the emergency department with three episodes of generalised tonic-clonic seizures for the last six hours. One day prior, she had headache and blurring of vision for which she approached the general practitioner and was advised to take analgesics and referred to a higher centre. There was no history of similar illness in the past and neither in any of the family members.

She was classified as a case of systemic sclerosis as per American College of Rheumatology / European League Against Rheumatism (ACR / EULAR) criteria one year back, when she had skin thickening on the hands and legs, Raynaud's phenomenon, and arthritis. Her autoimmune profile indicated antinuclear antibodies level of 1:320 speckled pattern, antitopoisomerase (anti-Scl 70), and anti -endothelial cell antibodies were positive. Her anti-centromere antibodies and anti-keratinocyte antibodies were negative. She was prescribed mycophenolate mofetil (MMF), prednisolone 10 $\mathrm{mg}$, and hydroxychloroquine $200 \mathrm{mg}$ daily for her disease control.

On examination in the emergency department, she was drowsy, confused with a GCS score of 12 [E-3 V-4 M-5], had a last episode of seizure 1 hour back. Her pulse was 100 / minute regular, blood pressure of 180 / $120 \mathrm{~mm}$ of mercury in right arm in supine position with normal respiratory rate. On neurological examination, her all deep tendon reflexes were brisk except ankle (could not be performed due to ulcer over Achilles tendon) and Babinski's sign was positive. She had skin thickening of both fingers and hands up to the metatarsophalangeal joints, an ulcer on fingertips and feet, with an ACR / EULAR Score of 17. There were no signs of pulmonary oedema or fluid overload. After stabilisation in the emergency department, her MRI brain was done. MRI disclosed vasogenic oedema in bilateral occipital and parietal which was suggestive of posterior reversible encephalopathy syndrome as shown in Figure 1.

\begin{tabular}{|ccccc|}
\hline Day & $\begin{array}{c}\text { Serum } \\
\text { Creatinine } \\
\text { (mg / dL) }\end{array}$ & $\begin{array}{c}\text { Serum Urea } \\
\text { (mg / dL) }\end{array}$ & $\begin{array}{c}\text { Serum } \\
\text { Sodium } \\
\text { (meq / L) }\end{array}$ & $\begin{array}{c}\text { Serum } \\
\text { Potassium } \\
\text { (meq / L) }\end{array}$ \\
\hline Day 1 & 2.4 & 73 & 134 & 3.5 \\
Day 2 & 2.5 & 96 & 130 & 4.0 \\
Day 3 & 4.7 & 151 & 133 & 3.3 \\
Day 4 & 3.8 & 147 & 129 & 6.0 \\
Day 5 & 3.8 & 133 & 133 & 3.4 \\
Day 6 & 3.0 & 112 & 140 & 4.5 \\
Day 7 & 3.0 & 109 & 132 & 3.8 \\
Day 8 & 2.4 & 108 & 131 & 4.0 \\
\hline Table 1. Kidney Function Test of the Patient during Hospital Stay \\
\hline \multicolumn{5}{r}{} \\
\hline \multicolumn{5}{c}{} \\
\hline
\end{tabular}

Her laboratory investigation revealed a haemoglobin of $13.3 \mathrm{~g} / \mathrm{dL}$, total white blood cells $-13,200$ / cu mm, blood urea-73 mg / dL, serum creatinine-2.1 mg / dL, lactate dehydrogenase $-394 \mathrm{mg} / \mathrm{dL}$. Her chest radiograph showed cardiomegaly. Her echocardiography revealed massive pericardial effusion with early tamponade. Her ultrasound of the kidney showed normal sizes with raised echo texture and maintained cortico-medullary differentiation. She was diagnosed as a case of scleroderma renal crisis with PRES and was started with intravenous labetalol, nitroglycerine, and anti-epileptics. Tab ramipril $5 \mathrm{mg}$ OD was started and titrated per blood pressure. Her steroids were withheld. Kidney function test (KFT) monitoring was done as shown in Table 1.
Her headache and vision improved on treatment and was discharged with creatinine of $2.4 \mathrm{mg} / \mathrm{dL}$. (Table 1).

\section{DISCUSSION OF MANAGEMENT}

During the hospital stay, she did not require dialysis. She was discharged on ramipril $5 \mathrm{mg}$ 10D, Tab MMF, and hydroxychloroquine. At one month follow up her disease activity and KFT were stable and she was doing well.

\section{DISCUSSION}

Posterior reversible encephalopathy syndrome is characterised by neurologic symptoms, including headache, blurred vision, altered consciousness, and seizure. 4 Our patient had all the above features. The typical neuroimaging finding of posterior reversible encephalopathy syndrome is vasogenic cerebral oedema with a primarily symmetrical distribution in the posterior lobes, including the occipital and parietal lobes. Similar findings were present in magnetic resonance imaging of our patient.

PRES was described first in 1996, in association with preeclampsia / eclampsia. Other causes of posterior reversible encephalopathy syndrome are accelerated hypertension, infections, sepsis, an autoimmune disorder like systemic lupus erythematous, Wegener's disease, chronic kidney disease, haemodialysis as well as immunosuppressive drugs (e.g., cyclosporine) and bone marrow transplantation. There are very few cases of scleroderma renal crisis presenting as posterior reversible encephalopathy syndrome.5,6

There are 2 main hypotheses regarding the mechanism of posterior reversible encephalopathy syndrome, scleroderma renal crisis. According to the first, severe hypertensioninduced cerebral hyper perfusion leads to autoregulation failure and vasogenic oedema in the brain; as per the second hypothesis, vasculopathy secondary to systemic sclerosis causes brain hypoperfusion leading to increased endothelial permeability and brain oedema. ${ }^{7-9}$ Posterior reversible encephalopathy syndrome is usually reversible once the underlying aetiology is identified and treated, along with blood pressure reduction. $3,10,7,11$

In a review of 13 cases of PRES related to connective tissue disease, it described 10 patients with systemic lupus erythematosus (SLE), 2 with Wegner's granulomatosis, and 1 with SSc. In 2016 Chen $C$ et al reported a review of 5 case reports of SRC presenting with PRES. As per their review, the mean age of their 5 patients was 33.2 years, and their clinical features were the same as seizures, confusion, and blurred vision. The mean arterial blood pressure at presentation was 140.6 (123 - 173) mm Hg. Two patients had diffuse cutaneous SSc, 1 had limited cutaneous SSc, 1 had SSc / SLE overlap syndrome, and 1 had unknown-type SSc. Our patient was significant at a young age and had a blood pressure of 180 / 120 which is more than other cases. She never had anaemia during her hospital stay, had diffuse cutaneous systemic sclerosis. Three of the 5 patients developed microangiopathic haemolytic anaemia. Scleroderma renal crisis is associated with haemolytic anaemia. In our case, patient had normal haemoglobin throughout the 8-day course. 
Out of five cases, 3 cases developed PRES after initiation of dialysis. Our case was not associated with dialysis. Currently, the angiotensin-converting enzyme inhibitor (ACEi) is the drug of choice for SRC, and we recommend continuing ACEi therapy for blood pressure control even if creatinine is in a rising trend. Our patient's serum creatinine rose for the initial three days after starting angiotensin converting enzyme inhibitors and then declined steadily.

\section{CONCLUSIONS}

Systemic sclerosis presenting with PRES is a very rare condition. Scleroderma renal crisis is a risk factor for PRES because of its association with hypertension and microangiopathy, both of which are pathogenic factors for PRES. Our case demonstrates that PRES can be reversed by lowering blood pressure using angiotensin-converting enzyme inhibitors even with deranged creatinine levels. Therefore, we endorse and emphasize that patients with SSc should be started with angiotensin-converting enzyme inhibitor therapy for the treatment of hypertension and to limit the deterioration of renal injury.

Financial or other competing interests: None.

Disclosure forms provided by the authors are available with the full text of this article at jemds.com.

\section{REFERENCES}

[1] Pradhan V, Rajadhyaksha A, Nadkar M, et al. Clinical and autoimmune profile of scleroderma patients from western India. Int J Rheumatol 2014;2014:983781.

[2] Chen CY, Hung SY, Lee YJ, et al. Delayed onset of posterior reversible encephalopathy syndrome in a case of scleroderma renal crisis with maintenance hemodialysis: case report and literature review. Medicine (Baltimore) 2016;95(52):e5725.
[3] Khan K, Bawankule S, Patil MM, et al. Case report: successful management of pres in patient of CKD. Indian Journal of Medical Case Reports 2019;8(2):4-7.

[4] Sato $\mathrm{Y}$, Ito $\mathrm{T}$, Iguchi $\mathrm{A}$, et al. Posterior reversible encephalopathy syndrome and microangiopathic haemolytic anaemia developing in a regularly haemodialysed patient with scleroderma renal crisis: a case report. Modern Rheumatology Case Reports 2019;3(2):124-9.

[5] Poon WL, Mok CC. Reversible posterior leucoencephalopathy in scleroderma. Ann Rheum Dis 2005;64(12):1803-4

[6] Kobatake M, Ishimaru N, Kanzawa $\mathrm{Y}$, et al. Recurring posterior reversible encephalopathy syndrome in a patient with polymyositis/systemic sclerosis overlap syndrome triggered by scleroderma renal crisis. Eur J Rheumatol 2019;6(3):158-60.

[7] Tonsawan P, Talabthong K, Puapairoj A, et al. Renal pathology and clinical associations in systemic sclerosis: a historical cohort study. Int J Gen Med 2019;12:323-31.

[8] Bawankule S, Kumar S, Gaidhane A, et al. Clinical profile of patients with hepatic encephalopathy in cirrhosis of liver. Journal of Datta Meghe Institute of Medical Sciences University 2019;14(3):130-6.

[9] Bhatia A, Bhagwat A, Acharya S, et al. Postpartum haemolytic uremic syndrome (PHUS) with Posterior Reversible Encephalopathy Syndrome (PRES) complicating pregnancy: a rare case report. Journal of Clinical \& Diagnostic Research 2019;13(4):0D01-03.

[10] Bartynski WS. Posterior reversible encephalopathy syndrome, part 1: fundamental imaging and clinical features. Am J Neuroradiol 2008;29(6):1036-42.

[11] Singhal S, Baheti A, Singh K, et al. Cortical blindness in posterior reversible encephalopathy syndrome in postpartum eclampsia. Indian Journal of Medical Specialities 2019;10(4):229-30. 